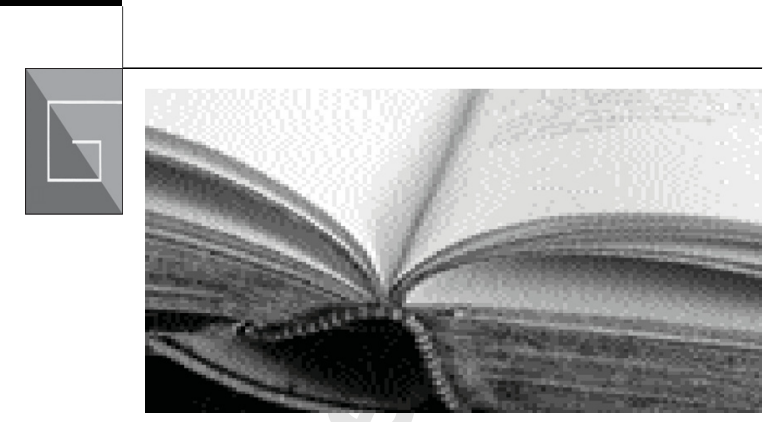

\title{
Langue commune, cultures distinctes. Les illusions du Globish
}

\author{
Geneviève Tréguer-Felten \\ Presses de l'Université Laval, coll. "Sciences de l'administration », \\ août 2018, 228 p., ISBN 978-2-7637-3795-9
}

$\mathrm{F}$

ace à l'accroissement exponentiel des échanges dû à la mondialisation des marchés, les entreprises sont confrontées au défi de la diversité linguistique. Pour répondre à ce défi, deux stratégies ont été développées : soit adopter une langue commune, soit consentir à la réalité de la diversité des langues et de cultures et opter pour l'entreprise multilingue. Pour des raisons de facilité et d'économie, la tendance des entreprises a jusqu'ici consisté à privilégier la première solution, celle du tout anglais. D'autres raisons ont aussi milité pour cette option. Notamment la reconnaissance de l'hégémonie de l'anglais comme langue des affaires, la domination du modèle anglosaxon dans les domaines politique, scientifique et commercial, sans oublier le poids de cette domination dans le monde éducatif du management, puissamment relayé par les Business Schools du monde entier qui ne jurent que par l'anglais.

Certes, le recours à une langue commune n'est pas aussi simple. Les politiques linguistiques des entreprises ne sont pas toujours bien respectées par tous les acteurs. Les grands groupes, et pas seulement eux, se doivent de prendre en compte les réalités locales des marchés. L'asymétrie des compétences linguistiques et culturelles du middle management et des cols bleus, voire dans certains cas du top management, les difficultés de circulation de l'information et du transfert des connaissances des maisonsmères vers les filiales et vice-versa, le nécessaire et couteux recours à la traduction, tout ceci pèse sur l'option monolingue. Néanmoins, l'entreprise multinationale est 
majoritairement « anglophone ». Ce qui ne veut pas dire qu'elle parle l'anglais, mais une variété d'anglais que les spécialistes appellent l'anglais lingua franca (ELF), voire localement l'Airbus English pour prendre l'exemple du géant de l'aéronautique européenne.

Globalement nous assistons donc à la domination d'une langue commune et on pourrait penser qu'avec cet outil commun les entreprises communiquent correctement. Cependant il s'avère que Babel est toujours là, qu'il ne suffit pas de parler pour se faire comprendre. C'est ce que démontre magistralement le livre de Geneviève TréguerFelten. Chassez la différence et elle revient au galop ! «Je parle la même langue que toi ». Certes, mais comme l'auteur l'indique dans un chapitre introductif, quand « je dis vert, tu comprends bleu ». A l'appui de sa thèse, l'auteur mobilise une scrupuleuse observation de l'autoreprésentation d'entreprises françaises et chinoises, alliée à une rigoureuse méthodologie de l'analyse du discours. Elle montre comment ces entreprises communiquent sur elles-mêmes, comment elles construisent leur « ethos », dans un anglais qu'elles s'imaginent transparent pour l'autre.

L'analyse du discours fondé sur les documents dissèque avec une précision chirurgicale les valeurs que ce discours véhicule. Or, les valeurs, c'est la culture. D'où le titre de l'ouvrage Langue commune, cultures distinctes. Et si l'entreprise mondialisée se targue naïvement de parler le « Globish », cet anglais « hors sol » et donc désincarné, elle oublie qu'elle reste enracinée dans sa propre culture. La langue commune, loin d'être la panacée attendue, ne parvient pas à masquer mais au contraire révèle la différence des cultures.

Avant d'illustrer sa thèse à l'aune de l'approche comparative de l'ethos des entreprises françaises et chinoises, domaine que l'auteur connaît très bien, Geneviève Tréguer-Felten analyse à l'aide d'exemples concrets et authentiques la langue des courriels pour montrer en quoi ils reflètent les styles de communication culturellement marqués, ratant ainsi leur cible étrangère, dépositaire d'une autre culture. L'ELF n'est aucunement associé aux communautés dont sont issus ses utilisateurs qui sans s'en rendre compte font appel à leurs propres univers de sens.

Le chapitre $7 \mathrm{du}$ livre illustre cette thèse à l'aide d'un exemple pratique, celui de la relation client. Et l'auteur de conclure « nous usons les uns et les autres de l'ELF, comme s'il s'agissait de notre propre langue maternelle ». L'auteur égratigne au passage une conception étroite de la traduction qui considère la langue comme un outil de communication transparent alors que traduire consiste à transposer un système discursif et culturel de la culture source vers la culture cible, comme l'ont montré les travaux récents de traductologie.

Cet ouvrage, très bien rédigé dans un langage clair et pas du tout jargonnant se veut une réflexion critique sur le langage, la culture et les modes de communication qu'ils incarnent. Les services de communication des entreprises tireront un grand profit de sa lecture.

Philippe LeComte Président du GEM\&L 